\title{
Comparison of published guidelines for management of coagulopathy and thrombosis in critically ill patients with COVID 19: implications for clinical practice and future investigations
}

\author{
Adam Flaczyk ${ }^{1}$, Rachel P. Rosovsky²*, Clay T. Reed ${ }^{3}$, Brittany K. Bankhead-Kendall ${ }^{4}$, Edward A. Bittner ${ }^{1}$ and \\ Marvin G. Chang ${ }^{5^{*}}$ (D)
}

\begin{abstract}
Critically ill patients with COVID-19 are at increased risk for thrombotic complications which has led to an intense debate surrounding their anticoagulation management. In the absence of data from randomized controlled clinical trials, a number of consensus guidelines and recommendations have been published to facilitate clinical decisionmaking on this issue. However, substantive differences exist between these guidelines which can be difficult for clinicians. This review briefly summarizes the major societal guidelines and compares their similarities and differences. A common theme in all of the recommendations is to take an individualized approach to patient management and a call for prospective randomized clinical trials to address important anticoagulation issues in this population.
\end{abstract}

Keywords: COVID-19, Coronavirus, Thrombosis, Anticoagulation, Venous thromboembolism, Hematologic monitoring, Therapeutic anticoagulation

\section{Introduction}

COVID-19-associated coagulopathy [1] is well established in COVID-19 patients and is marked by a state of profound inflammation with endothelial dysfunction, abnormal flow dynamics, platelet activation, and hypercoagulability resulting in higher rates of thrombotic complications such as deep venous thrombosis (DVT), pulmonary embolism (PE), and microvasculature thrombosis [2-5]. Given the evidence that COVID-19 patients

\footnotetext{
* Correspondence: rprosovsky@partners.org; mgchang@partners.org 2Division of Hematology and Oncology, Massachusetts General Hospital, 55 Fruit Street, Boston, MA, USA

${ }^{5}$ Division of Cardiac Anesthesia and Critical Care, Department of Anesthesia, Critical Care and Pain Medicine, Massachusetts General Hospital, Boston, USA Full list of author information is available at the end of the article
}

are at increased risk for thrombotic complications, a number of consensus guidelines and recommendations are now available to facilitate clinical decision-making. However, these guidelines are limited by their lack of data from randomized controlled clinical trials. This review provides an overview of major societal guidelines and recommendations that focus on prevention, monitoring, and treatment of COVID-19-associated coagulopathy (CAC). In addition, the similarities and differences between the guidelines are highlighted, and their implications for practice are explored. Lastly, proposed topics for future consideration and study are offered.

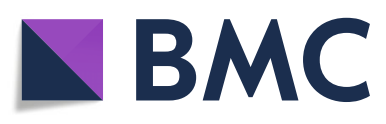

(c) The Author(s). 2020 Open Access This article is licensed under a Creative Commons Attribution 4.0 International License, which permits use, sharing, adaptation, distribution and reproduction in any medium or format, as long as you give appropriate credit to the original author(s) and the source, provide a link to the Creative Commons licence, and indicate if changes were made. The images or other third party material in this article are included in the article's Creative Commons licence, unless indicated otherwise in a credit line to the material. If material is not included in the article's Creative Commons licence and your intended use is not permitted by statutory regulation or exceeds the permitted use, you will need to obtain permission directly from the copyright holder. To view a copy of this licence, visit http://creativecommons.org/licenses/by/4.0/ The Creative Commons Public Domain Dedication waiver (http://creativecommons.org/publicdomain/zero/1.0/) applies to the data made available in this article, unless otherwise stated in a credit line to the data. 


\section{Current societal recommendations: similarities and differences}

We review seven major societal recommendations and guidelines addressing the management of coagulopathy in COVID-19 patients: the Centers for Disease Control and Prevention (CDC) [6], International Society on Thrombosis and Haemostasis interim guidance (ISTH-IG) [7], American Society of Hematology (ASH) [8, 9], American College of Chest Physicians (ACCP) [10], Scientific and Standardization Committee of ISTH (SCC-ISTH) [11], Anticoagulation Forum (ACF) [12], and American College of Cardiology (ACC) [13]. These recommendations and guidelines were specifically selected for review because of their focus on anticoagulation in critically ill patients. Moreover, each sponsoring organization has prior expertise in developing evidence-based guidelines and providing health-related recommendations in the arena of venous thromboembolism (VTE). The aims of the major societal recommendations and guidelines vary. The ISTH interim guidance is unique in that it provides guidance on the risk stratification for COVID-19 patients on admission and the management of coagulopathy based on laboratory parameters. Alternatively, ACF, ASH, CDC, ACCP, ACC, and SCC-ISTH offer guidance on in-hospital and postdischarge VTE prevention, treatment, and monitoring.

Tables 1, 2, 3, 4, 5, 6, and 7 highlights six major societal recommendations and guidelines on the management of CAC focusing on several critical care issues: (1) laboratory testing for risk stratification and triage, (2) use of biomarkers to guide anticoagulation, (3) proposals for alterations of standard prophylactic VTE anticoagulation regimens for the prevention of thrombotic complications, (4) examination of available medications preferred for anticoagulation, (5) considerations for initiation of therapeutic anticoagulation, (6) indications for thrombolytic therapy, (7) decision-making regarding withholding anticoagulation treatment, (8) use of mechanical thromboprophylaxis, (9) monitoring of anticoagulation, (10) duration of therapeutic anticoagulation, (11) necessity of anticoagulation at discharge, and (12) treatment of active bleeding. We specifically focus on the recommendations and guidelines for critical care patients if mentioned in the major societal guidelines and recommendations; otherwise, we include the highest acuity patient population (i.e., hospitalized patients). A comparison of the similarities and differences between the guidelines and recommendations on each of the critical issues is provided.

\section{Laboratory testing for risk stratification and triage}

Both ISTH-IG and ASH are the only societies that recommend monitoring D-dimer, PTT, platelet count, and fibrinogen levels for risk stratification of critical care
Table 1 Major societal recommendations regarding laboratory testing for risk stratification and triage

\begin{tabular}{|c|c|}
\hline \multicolumn{2}{|c|}{ Laboratory testing for risk stratification and triage } \\
\hline $\begin{array}{l}\text { Centers for Disease Control and } \\
\text { Prevention (CDC) guidelines [6] }\end{array}$ & $\begin{array}{l}\text { Mentions lack of prospective data } \\
\text { demonstrating laboratory testing in } \\
\text { risk stratification of patients who } \\
\text { are asymptomatic or with mild } \\
\text { infection. Mentions that there is } \\
\text { insufficient data to recommend for } \\
\text { or against using laboratory values } \\
\text { to guide management. }\end{array}$ \\
\hline $\begin{array}{l}\text { International Society for } \\
\text { Thrombosis AND Haemostasis's } \\
\text { interim guidance (ISTH-IG) [7] }\end{array}$ & $\begin{array}{l}\text { Recommends obtaining D-dimer, } \\
\text { PTT, platelet count, and fibrinogen } \\
\text { levels for all patients who present } \\
\text { with COVID-19 as the measurements } \\
\text { may be helpful for risk stratification } \\
\text { (D-dimer markedly raised three- to } \\
\text { fourfold, prothrombin time pro- } \\
\text { longed, platelet count < } 100 \times 10^{9} \text {, } \\
\text { and fibrinogen }<2.0 \mathrm{~g} / \mathrm{L} \text { ) of patients } \\
\text { who may need close monitoring and } \\
\text { admission to hospital. Monitoring of } \\
\text { parameters after admission may be } \\
\text { helpful as more aggressive critical } \\
\text { care treatment is warranted and ex- } \\
\text { perimental therapies should be con- } \\
\text { sidered if parameters worsen. }\end{array}$ \\
\hline
\end{tabular}

Anticoagulation Forum (ACF) Not mentioned

[12]

American Society of

Hematology (ASH) [8, 9]

Recommends monitoring D-dimer, $\mathrm{PTT}$, platelet count, and fibrinogen. Mentions that worsening of these parameters may predict more aggressive critical care and experimental therapies might be considered.

American College of Chest Physicians (ACCP) [10]

Scientific and Standardization Committee of ISTH (SCC-ISTH) [11]

Not mentioned

States further study is required. Acknowledges that use of very elevated D-dimer (> 6 times upper limit of normal) is a consistent predictor of thrombotic events and poor overall prognosis in this population.

American College of Cardiology Similar to other acutely ill medical (ACC) [13] patients without COVID-19. Regular monitoring of platelet count, PT, Ddimer, and fibrinogen is important to diagnose worsening coagulopathy. Mentions that the treatment of underlying conditions of $\mathrm{DIC}$ and bacterial superinfections is important.

Abbreviations: COVID-19 coronavirus disease 2019, DIC disseminated intravascular coagulation, $P T$ prothrombin time, $P T T$ partial thromboplastin time

treatment and consideration of experimental COVID-19 therapies based on changes in these parameters. ISTH-IG also recommends obtaining D-dimer, PTT, platelet count, and fibrinogen for all patients who present with COVID-19 infection to help guide which patients may require admission. Specifically, they provide an algorithm and the 
Table 2 Major societal recommendations regarding using biomarkers to guide anticoagulation

\begin{tabular}{ll}
\hline Biomarkers to guide anticoagulation \\
\hline CDC & $\begin{array}{l}\text { Insufficient data to recommend for or against using } \\
\text { hematologic and coagulation parameters to guide } \\
\text { management decisions. }\end{array}$ \\
ISTH-IG & Not mentioned \\
ACF & $\begin{array}{l}\text { Biomarker thresholds such as D-dimer for guiding anticoagula- } \\
\text { tion management should not be done outside the setting of }\end{array}$ \\
a clinical trial.
\end{tabular}

Abbreviations: COVID-19 coronavirus disease 2019, ROTEM rotational thromboelastometry, TEG thromboelastography, VTE venous thromboembolism

following thresholds for admission to the hospital: D-dimer markedly raised three- to fourfold, prothrombin time prolonged, platelet count $<100 \times 10^{9}$, and fibrinogen $<2.0 \mathrm{~g} / \mathrm{L}$. Alternatively, the CDC states that there is a lack of prospective data demonstrating laboratory measures of coagulopathy for risk stratification in patients who are asymptomatic or with mild infection, and insufficient data to recommend for or against using such laboratory values to guide management. The SCC-ISTH mentions that the risk stratification algorithm for hospitalized patients requires further study while acknowledging the use of very elevated D-dimer ( 6 times upper limit of normal (ULN)) appears to be a consistent predictor of thrombotic events and poor overall prognosis in this patient population. ACC recommends that risk stratification of COVID-19 patients should be similar to other acutely ill medical patients without COVID-19 while stating that regular monitoring of platelet count, PT, D-dimer, and fibrinogen is important to diagnosing worsening coagulopathy and treatment of underlying conditions of DIC and bacterial superinfections is important.

\section{Using biomarkers to guide intensity of anticoagulation}

None of the societies recommend daily monitoring of biomarkers as a means to guide intensity of anticoagulation management. The ACF states that biomarker thresholds such as D-dimer for guiding anticoagulation management should not be done outside the setting of a clinical trial. Similarly, the SCC-ISTH remarks that D- dimer levels should not be used to solely to guide anticoagulation regimens. Only ASH and ACC address the issue of anticoagulation in patients with lupus anticoagulant inhibitors. ASH recommends that those patients be treated with prophylactic anticoagulation regimens similar to other hospitalized patients, and ACC mentions that further investigation is required to determine the role of antiphospholipid antibodies in pathophysiology of CAC. ASH also mentions that thromboelastography (TEG) and rotational thromboelastometry (ROTEM) are currently under investigation for CAC and disseminated intravascular coagulopathy (DIC) and should not be used routinely to guide management. The ACC mentions that D-dimer $>2$ times ULN may suggest that patient is at high risk for VTE and to consider extended prophylaxis (up to 45 days) in patients with low risk of bleeding.

\section{Alterations from standard venous thromboembolism anticoagulation regimens to prevent thrombotic complications}

None of the major societies recommend therapeutic anticoagulation for prevention of thrombotic complications. Only the ACF recommends increasing the intensity of anticoagulation in critically ill patients (enoxaparin $40 \mathrm{mg}$ twice daily or heparin $7500 \mathrm{unit} /$ dose three times daily) while they recommend standard dose anticoagulant prophylaxis for all other hospitalized noncritically ill patients. The SCC-ISTH mentions that intermediate LMWH dosing can be considered in high risk critically ill patients (50\% of respondents) and may be considered in non-critically ill hospitalized patients (30\% of respondents). The SCC-ISTH also specifically mentions that the anticoagulation regimens may be modified based on extremes of body weight $(50 \%$ increase in dose if obese), severe thrombocytopenia, or worsening renal function. The ACC mentions that while there is insufficient data to consider routine intermediate or therapeutic dosing, a minority of their panel considers an intermediate intensity (31.6\%; i.e., enoxaparin $1 \mathrm{mg} /$ $\mathrm{kg} /$ day, enoxaparin $40 \mathrm{mg}$ BID, UFH with target PTT $50-70)$ or therapeutic anticoagulation (5.2\%) reasonable. The CDC recommends that any changes in anticoagulation regimens that are different than the current standard of care for patients without COVID-19 should only be administered in the setting of a clinical trial.

\section{Preferred medication regimens for prophylactic anticoagulation}

Many of the societies recommend using once daily prophylactic anticoagulants to reduce healthcare worker exposure. The ISTH-IG, ASH, and ACCP recommend using LMWH in critically ill patients. ASH particularly mentions that LMWH is preferred over UFH to reduce 
Table 3 CDC and societal recommendations regarding thrombotic prophylaxis and treatment in COVID-19

\begin{tabular}{|c|c|c|}
\hline & VTE prophylaxis regimen and preferred medications & $\begin{array}{l}\text { Therapeutic anticoagulation regimens and preferred } \\
\text { medications }\end{array}$ \\
\hline $\mathrm{CDC}$ & $\begin{array}{l}\text { LMWH or UFH (standard dosing). Insufficient data to recommend } \\
\text { for or against the increase of anticoagulation intensity outside of a } \\
\text { clinical trial. }\end{array}$ & Standard regimens for non-COVID-19 patients. \\
\hline ISTH-IG & LMWH (standard dosing) & Not mentioned \\
\hline ACF & $\begin{array}{l}\text { Suggests an increased intensity of venous thromboprophylaxis be } \\
\text { considered for critically ill patients }{ }^{\#} \text { (i.e., LMWH } 40 \text { mg SC twice } \\
\text { daily, LMWH } 0.5 \mathrm{mg} / \mathrm{kg} \text { subcutaneous twice daily, heparin } 7500 \text { SC } \\
\text { three times daily, or low-intensity heparin infusion) that they state is } \\
\text { based largely on expert opinion. }\end{array}$ & $\begin{array}{l}\text { LMWH over UFH whenever possible to avoid additional laboratory } \\
\text { monitoring, exposure, and personal protective equipment. In } \\
\text { patients with AKI or creatinine clearance }<15-30 \mathrm{~mL} / \mathrm{min} \text {, UFH is } \\
\text { recommended over } \mathrm{LMWH} \text {. }\end{array}$ \\
\hline ASH & $\begin{array}{l}\text { LMWH over UFH (standard dosing) to reduce exposure unless risk } \\
\text { of bleeding outweighs risk of thrombosis. }\end{array}$ & $\begin{array}{l}\text { LMWH or UFH over direct oral anticoagulants due to reduced drug- } \\
\text { drug interactions and shorter half-life. }\end{array}$ \\
\hline ACCP & LMWH (standard dosing) & $\begin{array}{l}\text { LMWH or fondaparinux over UFH. UFH preferred in patients at high } \\
\text { bleeding risk and in renal failure or needing imminent procedures. } \\
\text { Recommend increasing dose of LMWH by } 25-30 \% \text { in patients with } \\
\text { recurrent VTE despite therapeutic LMWH anticoagulation. }\end{array}$ \\
\hline SCC-ISTH & $\begin{array}{l}\text { LMWH or UFH. Intermediate intensity LMWH can be considered in } \\
\text { high risk critically ill patients ( } 50 \% \text { of responders) and may be } \\
\text { considered in non-critically ill hospitalized patients ( } 30 \% \text { of respon- } \\
\text { dents). Mentions that there are several advantages of LMWH over } \\
\text { UFH including once vs twice or more injections and less heparin- } \\
\text { induced thrombocytopenia. Regimens may be modified based on } \\
\text { extremes of body weight (50\% increase in dose if obese), severe } \\
\text { thrombocytopenia*, or worsening renal function. }\end{array}$ & Not mentioned \\
\hline ACC & $\begin{array}{l}\text { Enoxaparin } 40 \mathrm{mg} \text { daily or similar LMWH regimen (i.e., dalteparin } \\
5000 \mathrm{u} \text { daily) can be administered with consideration of SC heparin } \\
(5000 \mathrm{u} \text { twice to three times per day) in patients with renal } \\
\text { dysfunction (i.e., creatinine clearance }<30 \mathrm{~mL} / \mathrm{min} \text { ). Once daily } \\
\text { regimens of LMWH may be advantageous over UFH to reduce } \\
\text { missed doses associated with worse outcomes, reduce healthcare } \\
\text { worker exposure, and conserve personal protective equipment. } \\
\text { There is insufficient data to consider routine therapeutic or } \\
\text { intermediate dose parenteral anticoagulation with UFH or LMWH. } \\
\text { Only a minority of the panel considered intermediate intensity } \\
\text { (31.6\%; i.e., enoxaparin } 1 \mathrm{mg} / \mathrm{kg} / \text { day, enoxaparin } 40 \mathrm{mg} \mathrm{BID,} \mathrm{UFH} \\
\text { with target PTT 50-70) to therapeutic anticoagulation (5.2\%) } \\
\text { reasonable. }\end{array}$ & $\begin{array}{l}\text { Medication regimen likely to change depending on comorbidities } \\
\text { (i.e., renal or hepatic dysfunction, gastrointestinal function, } \\
\text { thrombocytopenia). Parenteral anticoagulation (i.e., UFH) may be } \\
\text { preferred in many ill patients given it may be withheld temporarily } \\
\text { and has no known drug-drug interactions with COVID-19 therapies. } \\
\text { LMWH may be preferred in patients who are unlikely to need pro- } \\
\text { cedures as there are concerns with UFH regarding the time to } \\
\text { achieve therapeutic PTT and increased exposure to healthcare } \\
\text { workers. DOACs have advantages including lack of monitoring that } \\
\text { is ideal for outpatient management but may have risks in settings } \\
\text { of organ dysfunction related to clinical deterioration and lack of } \\
\text { timely reversal at some centers. }\end{array}$ \\
\hline
\end{tabular}

Abbreviations: $A K I$ acute kidney injury, BID twice daily, DOAC direct oral anticoagulant, i.e. for example, $\mathrm{kg}$ kilograms, $L M W H$ low molecular weight heparin, mg milligram, min minute, $m L$ milliliter, PTT partial prothrombin time, $u$ units, SC subcutaneous, UFH unfractionated heparin, VTE venous thromboembolism *Platelet count not defined

\#For non-critically ill hospitalized patients, standard dose thromboprophylaxis regimens are recommended

exposure unless the risk of bleeding outweighs the risk of thrombosis. The CDC, ACF, and SCC-ISTH recommend LMWH or UFH with the rationale provided by the CDC being due to their short half-lives, versatility in administration (IV or subcutaneously), and less drugdrug interactions compared to oral anticoagulants. The SCC does particularly mention that there are several advantages of LMWH over UFH including once vs twice or more injections and less heparin-induced thrombocytopenia. Similarly, the ACC mentions that enoxaparin $40 \mathrm{mg}$ daily or similar LMWH regimen (i.e., dalteparin $5000 \mathrm{u}$ daily) can be administered with consideration of subcutaneous heparin $(5000 \mathrm{u}$ twice to three times per day) in patients with renal dysfunction (i.e., creatinine clearance $<30 \mathrm{~mL} / \mathrm{min}$ ). They mention that once daily regimens of LMWH may be advantageous over UFH to reduce missed doses associated with worse outcomes, reduce healthcare worker exposure, and conserve personal protective equipment. None of the societies recommend routine use of direct oral anticoagulants because of potential drug-drug interactions, renal and hepatic function abnormalities that have implications on pharmacodynamics, longer half-lives, cost implications, and/or lack of reversal agents in some hospitals (specifically mentioned in CDC, SCC-ISTH, Anticoagulation Forum, and ACCP guidelines).

\section{Preferred medications regimens for therapeutic anticoagulation}

The ACF and ACCP generally prefer LMWH over UFH to decreases staff exposure and laboratory monitoring. The ACCP also prefers fondaparinux over UFH and mentions that UFH may be preferred in patients at high bleeding risk, with renal failure or needing imminent 
Table 4 CDC and societal recommendations regarding thrombotic prophylaxis and treatment in COVID-19

\begin{tabular}{lll}
\hline & When to hold anticoagulation & When to use mechanical thromboprophylaxis \\
\hline CDC & Active hemorrhage or severe thrombocytopenia* & Not mentioned \\
ISTH-IG & $\begin{array}{l}\text { Hold when signs of active bleeding or platelet } \\
\text { count }<25 \times 10^{9} / \mathrm{L} \text {. Abnormal PT or PTT is not a } \\
\text { contraindication to thromboprophylaxis. }\end{array}$ & Not mentioned \\
Active bleeding or profound thrombocytopenia* & \\
& & $\begin{array}{l}\text { Recommends intermittent pneumatic compression in } \\
\text { patients with contraindication to pharmacological } \\
\text { thromboprophylaxis. Mentions that it is reasonable to } \\
\text { consider both mechanical and pharmacological }\end{array}$ \\
& thromboprophylaxis in critically ill patients if no \\
& contraindication exists for each modality.
\end{tabular}

$\begin{array}{ll}\text { ASH } & \text { Thromboprophylaxis is recommended even with } \\ \text { abnormal coagulation tests in the absence of active } \\ \text { bleeding and held only if platelet count }<25 \times 10^{9} / \mathrm{L} \\ \text { or fibrinogen }<0.5 \mathrm{~g} / \mathrm{L} \text {. Abnormal PT or PTा is not a } \\ \text { contraindication to thromboprophylaxis. Therapeutic } \\ \text { anticoagulation may need to be held if platelet count } \\ \\ <30-50 \times 10^{9} / \mathrm{L} \text { or fibrinogen }<1.0 \mathrm{~g} / \mathrm{L} \text {. } \\ \text { ACCP } & \text { Not mentioned }\end{array}$

SCC-ISTH No specific recommendations. Reports that $50 \%$ of respondents report holding if platelet count $<25 \times 10^{9} / \mathrm{L}$.
ACC

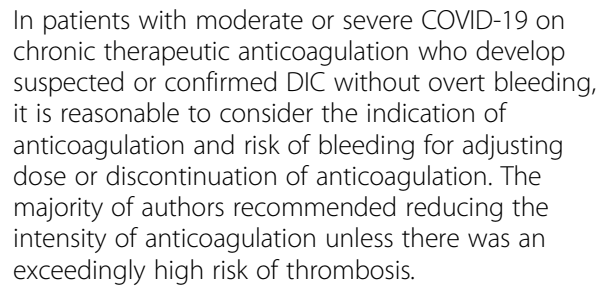
Recommends mechanical thromboprophylaxis (i.e.,
pneumatic compression devices) when pharmacological
thromboprophylaxis is contraindicated.

\section{When to use mechanical thromboprophylaxis}

Recommends intermittent pneumatic compression in thromboprophylaxis. Mentions that it is reasonable to thromboprophylaxis in critically ill patients if no contraindication exists for each modality.

Suggest the use of mechanical thromboprophylaxis in
critically ill patients who have a contraindication to
pharmacological thromboprophylaxis. Suggest against
the additional use of mechanical thromboprophylaxis in
critically ill patients receiving pharmacological prophylaxis
while mentioning that its addition is likely not to cause
harm.

Mechanical thromboprophylaxis (intermittent pneumatic compression devices preferred) should be used when pharmacological therapy contraindicated. Multimodal thromboprophylaxis with mechanical methods (i.e., intermittent pneumonic compression devices) should be considered ( $60 \%$ of respondents).

Mechanical thromboprophylaxis (intermittent pneumatic compression) should be considered in immobilized patients if pharmacological prophylaxis is contraindicated. Majority of panel members (55\%) considered the use of both pharmacological thromboprophylaxis and intermittent pneumatic compression reasonable while acknowledging a lack of high-quality evidence.

Abbreviations: COVID-19 coronavirus disease 2019, i.e. for example, $g$ gram, $L$ liter, $P T$ prothrombin time, PTT partial thromboplastin time

*Platelet count not defined

procedures. Similarly, the ACF recommends UFH over LMWH in patients with AKI or creatinine clearance $<15-30 \mathrm{~mL} / \mathrm{min}$. ASH mentions that LMWH or UFH is preferred over oral anticoagulants due to potential drug-drug interactions and their shorter half-lives. The SCC-ISTH and ISTH-IG do not mention preferred medication regimens for therapeutic anticoagulation. The $\mathrm{CDC}$ mentions that standard regimens for patients without COVID-19 patients should be used. The ACC mentions that the medication regimen is likely to change depending on comorbidities (i.e., renal or hepatic dysfunction, gastrointestinal function, thrombocytopenia). They give no particular preference to an agent but do mention that (1) parenteral anticoagulation (i.e., UFH) may be preferred in many ill patients given it may be withheld temporarily and has no known drug-drug interactions with COVID-19 therapies, (2) LMWH may be preferred in patients who are unlikely to need procedures as there are concerns with UFH regarding the time to achieve therapeutic PTT and increased exposure to healthcare workers, and (3) direct oral anticoagulants (DOAC) have advantages including lack of monitoring that are ideal for outpatient management but have risks in settings of organ dysfunction related to clinical deterioration and lack of timely reversal at some centers.

\section{Withholding anticoagulation}

Most of the major societal guidelines and recommendations (ISTH-IG, ACF, CDC, and ASH) advise holding anticoagulation in patients who are actively bleeding or severely thrombocytopenic. ISTH-IG recommends holding LMWH prophylactic anticoagulation for patients 
Table 5 CDC and societal recommendations regarding therapeutic anticoagulation and thrombolytic therapy in COVID-19

\begin{tabular}{|c|c|c|c|}
\hline & $\begin{array}{l}\text { When to consider therapeutic } \\
\text { anticoagulation }\end{array}$ & When to consider thrombolytics & $\begin{array}{l}\text { Duration of therapeutic } \\
\text { anticoagulation }\end{array}$ \\
\hline $\mathrm{CDC}$ & $\begin{array}{l}\text { Consider when a clinically suspected } \\
\text { thromboembolic event is present or } \\
\text { highly suspected despite imaging } \\
\text { confirmation. Insufficient data to } \\
\text { recommend for or against the } \\
\text { increase of anticoagulation intensity } \\
\text { outside the context of a clinical trial. } \\
\text { Mentions patients who have } \\
\text { thrombosis of catheters or extracorporeal } \\
\text { filters should be treated accordingly to } \\
\text { standard institutional protocols for } \\
\text { patients without COVID-19. }\end{array}$ & $\begin{array}{l}\text { Insufficient data to recommend } \\
\text { for or against thrombolytic therapy } \\
\text { outside the context of a clinical trial. } \\
\text { In pregnant patients, thrombolytic } \\
\text { therapy should only be used for } \\
\text { acute PE with life-threatening } \\
\text { hemodynamic instability due to risk } \\
\text { for maternal hemorrhage. }\end{array}$ & Not mentioned \\
\hline ISTH-IG & No specific recommendations & Not mentioned & Not mentioned \\
\hline ACF & $\begin{array}{l}\text { Consider when a clinically suspected } \\
\text { thromboembolic event is present or } \\
\text { highly suspected despite imaging } \\
\text { confirmation. }\end{array}$ & $\begin{array}{l}\text { Consider if clinical indication such } \\
\text { as STEMI, acute ischemic stroke, or } \\
\text { high risk massive PE with } \\
\text { hemodynamic instability. Otherwise, } \\
\text { it is not recommended outside } \\
\text { context of a clinical trial. }\end{array}$ & $\begin{array}{l}\text { A minimum of 3-month } \\
\text { course for anyone who was } \\
\text { initiated on anticoagulation } \\
\text { during hospitalization } \\
\text { (exception is recent bleeding } \\
\text { or high bleeding risk). Delayed } \\
\text { imaging should not be used to } \\
\text { determine anticoagulation } \\
\text { duration. Existing guidelines for } \\
\text { presumed hospital-associated } \\
\text { thromboembolic event should } \\
\text { be used to determine } \\
\text { anticoagulation beyond the } \\
\text { initial 3-month period. }\end{array}$ \\
\hline
\end{tabular}

ASH Consider increasing the intensity of anticoagulation regimen (i.e., from standard to intermediate intensity, from intermediate to therapeutic intensity) or change anticoagulants in patients who have recurrent thrombosis of catheters and extracorporeal circuits (i.e., ECMO, CRRT) on prophylactic anticoagulation regimens.

ACCP

Patients with PE or proximal DVT.

SCC-ISTH

Therapeutic anticoagulation should not be considered for primary prevention until randomized controlled trials are available. Increased intensity of anticoagulation regimen (i.e., from standard or intermediate intensity to therapeutic intensity) can be considered in patients without confirmed VTE or PE but have deteriorating pulmonary status or ARDS.

ACC

Mentions that therapeutic anticoagulation is the key to VTE treatment. Does not make distinction between confirmed or suspected VTE. Hemodynamically stable patients with submassive PE should receive anticoagulation rather than
Not mentioned

Not mentioned
Thrombolytics over no such therapy in patients with objectively confirmed PE with hemodynamic instability or signs of obstructive shock who are thrombolysis recommended over catheter-directed thrombolysis.

Not mentioned not at high risk of bleeding. Peripheral
Minimum of 3 months

Minimum of 3 'months
A multidisciplinary PERT may be helpful for intermediate and high risk patient with VTE. For hemodynamically high risk $P E$, systemic fibrinolysis is indicated with catheter-based therapies reserved for situations that are not amenable to systemic fibrinolysis.
Not mentioned 
Table 5 CDC and societal recommendations regarding therapeutic anticoagulation and thrombolytic therapy in COVID-19 (Continued)

\begin{tabular}{|c|c|c|}
\hline $\begin{array}{l}\text { When to consider therapeutic } \\
\text { anticoagulation }\end{array}$ & When to consider thrombolytics & $\begin{array}{l}\text { Duration of therapeutic } \\
\text { anticoagulation }\end{array}$ \\
\hline fibrinolytics. & $\begin{array}{l}\text { Patients with hemodynamically stable } \\
\text { intermediate-low or intermediate-high } \\
\text { risk PE should receive anticoagulation, } \\
\text { and rescue systemic fibrinolysis should } \\
\text { be considered in cases of further } \\
\text { deterioration with catheter-directed } \\
\text { therapies as an alternative. Catheter- } \\
\text { directed therapies should be limited } \\
\text { to most critical situations given } \\
\text { minimal data showing mortality benefit. } \\
\text { When considering fibrinolysis vs } \\
\text { percutaneous coronary intervention for } \\
\text { STEMI, clinicians should weigh risks and } \\
\text { severity of STEMI presentation, severity } \\
\text { of COVID-19 in patient, risk of COVID-19 } \\
\text { to individual clinicians and healthcare } \\
\text { system. }\end{array}$ & \\
\hline
\end{tabular}

Abbreviations: ARDS acute respiratory distress syndrome, COVID-19 coronavirus disease 2019, CRRT continuous renal replacement therapy, DVT deep vein thrombosis, ECMO extracorporeal membrane oxygenation, i.e. for example, PE pulmonary embolism, PERT pulmonary embolism response team, STEMI ST elevation myocardial infarction, VTE venous thromboembolism

with platelet count less than $25 \times 10^{9} / \mathrm{L}$. ASH mentions that therapeutic anticoagulation should be held if platelet count $<30-50 \times 10^{9} / \mathrm{L}$ or fibrinogen $<1.0 \mathrm{~g} / \mathrm{L}$, and prophylactic anticoagulation should be held only if platelet count $<25 \times 10^{9} / \mathrm{L}$ or fibrinogen $<0.5 \mathrm{~g} / \mathrm{L}$. The SCCISTH does not recommend a particular platelet level to hold anticoagulation but does report that $50 \%$ of their respondents report holding for a platelet count $<25 \times 10^{9} / \mathrm{L}$.
While the CDC and ACF recommend holding prophylactic anticoagulation in patients who are severely thrombocytopenic, they also do not recommend a particular platelet count threshold. The ACCP does not make any specific recommendations regarding the holding of anticoagulation. The ACC mentions that in patients with moderate or severe COVID-19 on chronic therapeutic anticoagulation who develop suspected or confirmed DIC

Table 6 CDC and societal recommendations regarding monitoring of anticoagulation in COVID-19

\begin{tabular}{llll}
\hline & $\begin{array}{l}\text { Monitoring of patients receiving } \\
\text { LMWH }\end{array}$ & $\begin{array}{l}\text { Monitoring of patients with } \\
\text { elevated PTT receiving } \\
\text { therapeutic anticoagulation }\end{array}$ & $\begin{array}{l}\text { Monitoring of patients receiving } \\
\text { therapeutic anticoagulation }\end{array}$ \\
\hline CDC & Not mentioned & Not mentioned & Per standard of care for patients \\
ISTH-IG & Advised in patients with severe & Not mentioned COVID-19 & Not mentioned
\end{tabular}

ACF renal impairment

Do not recommend dosing based on anti-Xa levels given lack of evidence on outcomes for thrombosis or bleeding

$\begin{array}{ll}\text { ASH } & \text { Not mentioned } \\ \text { ACCP } & \begin{array}{l}\text { Body weight adjusted doses for } \\ \text { LMWH do not require laboratory } \\ \text { monitoring in majority of patients }\end{array} \\ \text { SCC-ISTH } & \text { No specific recommendations. } \\ & \text { Mentions that LMWH may be } \\ & \text { advantageous over other agents } \\ & \text { for parenteral anticoagulation } \\ & \text { due to lack of routine monitoring }\end{array}$

ACC

Not mentioned

\begin{abstract}
May necessitate anti-Xa monitoring of UFH given artefactual increases in PTT.
\end{abstract}

Not mentioned

Not mentioned

Recommend monitoring anti-Xa receiving UFH. LMWH use allows additional monitoring to be avoided.

Not mentioned
Recommend monitoring anti-Xa levels to monitor UFH due to potential baseline PTT abnormalities. Reasonable to monitor anti-Xa or PTT in patients with normal baseline PTT levels and do not exhibit heparin resistance $(>35,000 \mathrm{u}$ heparin over $24 \mathrm{~h}$ ).

May necessitate anti-Xa monitoring of UFH given artefactual increases in PTT.

Monitor anti-Xa levels in all patients receiving UFH given potential of heparin resistance.

No specific recommendations. Mentions that expert clinical guidance statements and clinical pathways from large academic healthcare systems target an anti-factor Xa level of $0.3-0.7 \mathrm{IU} / \mathrm{mL}$ for UFH.

Not mentioned 
Table 7 CDC and societal recommendations regarding anticoagulation on discharge and correction of active bleeding in COVID-19

\begin{tabular}{|c|c|c|}
\hline & $\begin{array}{l}\text { Recommendations regarding anticoagulation on } \\
\text { discharge }\end{array}$ & Correction of active bleeding \\
\hline $\mathrm{CDC}$ & $\begin{array}{l}\text { Routine venous thromboprophylaxis post-discharge } \\
\text { is not recommended. FDA-approved prophylactic } \\
\text { anticoagulation regimen (rivaroxaban and betrixaban) } \\
\text { can be considered if high risk for VTE and low risk } \\
\text { for bleeding using criteria from clinical trials. }\end{array}$ & Not mentioned \\
\hline ISTH-IG & No specific recommendations & $\begin{array}{l}\text { Transfuse to keep platelet count }>50 \times 10^{9} / \mathrm{L} \text {, } \\
\text { fibrinogen }>1.5 \mathrm{~g} / \mathrm{L} \text {, PT ratio }<1.5\end{array}$ \\
\hline $\mathrm{ACF}$ & $\begin{array}{l}\text { No evidence for anticoagulation beyond } \\
\text { hospitalization, but reasonable to consider if low } \\
\text { risk for bleeding and high risk for VTE including } \\
\text { intubated, sedated, and paralyzed for multiple days. }\end{array}$ & Not mentioned \\
\hline ASH & $\begin{array}{l}\text { Reasonable to consider FDA-approved } \\
\text { post-discharge prophylactic anticoagulation } \\
\text { regimen (rivaroxaban and betrixaban) or } \\
\text { aspirin if criteria from trials for post-discharge } \\
\text { thromboprophylaxis are met. }\end{array}$ & $\begin{array}{l}\text { Transfuse one adult unit of platelets if platelets } \\
<50 \times 10^{9} / \mathrm{L} \text {, give } 4 \text { units of plasma if INR }>1.8 \text {, } \\
\text { and fibrinogen concentrate }(4 \mathrm{~g}) \text { or cryoprecipitate } \\
(10 \mathrm{u}) \text { if fibrinogen }<1.5 \mathrm{~g} / \mathrm{L} \text {. In patients with severe } \\
\text { coagulopathy and bleeding can consider } 4 \mathrm{~F}-\mathrm{PCC} \\
(25 \mathrm{u} / \mathrm{kg}) \text { instead of plasma. }\end{array}$ \\
\hline ACCP & $\begin{array}{l}\text { Can be considered in patients who are at low risk } \\
\text { of bleeding if emerging data suggests a clinical } \\
\text { benefit. }\end{array}$ & Not mentioned \\
\hline SCC-ISTH & $\begin{array}{l}\text { Either LMWH or FDA-approved post-discharge } \\
\text { prophylactic anticoagulation regimen } \\
\text { (rivaroxaban and betrixaban) should be } \\
\text { considered in patients with high VTE risk criteria. } \\
\text { Duration is } 14 \text { days at least and up to } 30 \text { days. } \\
\text { Of note, they report that none of the respondents } \\
\text { recommended aspirin for post-discharge } \\
\text { thromboprophylaxis. }\end{array}$ & Not mentioned \\
\hline ACC & $\begin{array}{l}\text { Reasonable to consider extended prophylaxis } \\
\text { with } L M W H \text { or DOACs for up to } 45 \text { days in } \\
\text { patients at high risk for VTE (i.e., D-dimer } \\
>2 \text { times the upper limit, reduced mobility, } \\
\text { active cancer) and low risk of bleeding. }\end{array}$ & $\begin{array}{l}\text { Transfuse platelets to maintain platelets }>50 \times 10^{9} / \mathrm{L} \\
\text { in DIC and active bleeding or if platelets }<20 \times 10^{9} / \mathrm{L} \\
\text { in patients at high risk of bleeding or requiring invasive } \\
\text { procedures. FFP (15 to } 25 \mathrm{~mL} / \mathrm{kg} \text { ) in patients with active } \\
\text { bleeding with either prolonged PT or PTT ratios } \\
\text { (> } 1.5 \text { times normal) or decreased fibrinogen }(<1.5 \mathrm{~g} / \mathrm{L}) \text {. } \\
\text { Fibrinogen concentrate or cryoprecipitate in patients } \\
\text { with persisting severe hypofibrinogenemia }(<1.5 \mathrm{~g} / \mathrm{L}) \text {. } \\
\text { Prothrombin complex concentrate if FFP is not possible. } \\
\text { Tranexamic acid should not be used routinely in patients } \\
\text { with COVID-19-associated DIC given the existing data. }\end{array}$ \\
\hline
\end{tabular}

Abbreviations: COVID-19 coronavirus disease 2019, DIC disseminated intravascular coagulation, DOAC direct oral anticoagulant, FDA Food and Drug Administration, FFP fresh frozen plasma, $g$ grams, $k g$ kilograms, PT prothrombin time, VTE venous thromboembolism, INR international normalized ratio, $L$ liter, $L M W H$ low molecular weight heparin, $m L$ milliliter, $P T$ prothrombin time, $P T T$ partial prothrombin time, $u$ units, $4 F-P C C$ four-factor prothrombin complex concentrate

with overt bleeding, it is reasonable to consider the indication of anticoagulation and risk of bleeding for adjusting dose or discontinuation of anticoagulation. The majority of their authors recommend reducing the intensity of anticoagulation unless there is an exceedingly high risk of thrombosis. Of note, the ISTH-IG, ACF, and ASH mention that abnormal PT or PTT is not a contraindication to thromboprophylaxis.

\section{Use of mechanical thromboprophylaxis}

The ACF, ASH, ACCP, ACC, and SCC-ISTH recommend or suggest mechanical thromboprophylaxis when pharmacological thromboprophylaxis is contraindicated. The ACF, ASH, ACC, and SCC-ISTH particularly mention pneumatic compression devices as examples of mechanical thromboprophylaxis. The
ACF mentions that it is reasonable to consider both mechanical and pharmacological thromboprophylaxis in critically ill patients if no contraindication exists for each modality. The SCC-ISTH mentions that multimodal thromboprophylaxis with mechanical methods (i.e., intermittent pneumonic compression devices) should be considered (60\% of respondents). Similarly, the majority of ACC panel members (55\%) considered the use of both pharmacological thromboprophylaxis and intermittent pneumatic compression reasonable while acknowledging a lack of high-quality evidence. The ACCP suggests against the additional use of mechanical thromboprophylaxis in critically ill patients receiving pharmacological prophylaxis while mentioning that its addition is likely not to cause harm. The CDC and ISTH-IG do not mention any 
recommendations or suggestions regarding the use of mechanical thromboprophylaxis.

\section{Considerations for therapeutic anticoagulation}

The CDC, ACCP, and ACF do not recommend therapeutic anticoagulation except in cases where there is a thromboembolic event or a high suspicion for a thromboembolic event when imaging is not possible. ASH recommends therapeutic anticoagulation only if there is a documented clinical indication (e.g., VTE, atrial fibrillation, or mechanical valve). ACC mentions that therapeutic anticoagulation is the key to VTE treatment but does not make a distinction between confirmed or suspected VTE. They do mention that hemodynamically stable patients with intermediate-low to intermediate-high risk PE should be managed initially with anticoagulation and close monitoring rather than fibrinolytics. While the SCC-ISTH recommends that therapeutic anticoagulation should not be considered for primary prevention until randomized trials are available, they do mention that therapeutic anticoagulation (i.e., changing from standard or intermediate intensity to therapeutic intensity) can be considered in patients without confirmed VTE but who have deteriorating pulmonary or ARDS. ASH also states that it is reasonable to consider increasing the intensity of the patient's anticoagulation regimen (i.e., from standard to intermediate intensity, from intermediate to therapeutic intensity) or change anticoagulants in patients who have recurrent thrombosis of catheters and extracorporeal circuits (i.e., ECMO, CRRT) on prophylactic anticoagulation regimens. Similarly, the ACCP recommends increasing the dose of LMWH by $25-30 \%$ in patients with recurrent VTE despite being on therapeutic LMWH anticoagulation. The CDC specifically mentions that patients who have thrombosis of catheters or extracorporeal filters should be treated accordingly to standard institutional protocols for patients without COVID-19.

\section{Considerations for thrombolytic treatment?}

The ACF recommends against the use of thrombolytics outside of a clinical trial unless there is a clinical indication for which it is already approved such as ST elevation myocardial infarction, acute ischemic stroke, or massive PE with hemodynamic instability. The CDC also mentions that there is insufficient data to recommend for or against thrombolytic therapy outside the context of a clinical trial. However, the CDC specifically mentions that in pregnant patients in particular, thrombolytic therapy should only be used for acute PE with lifethreatening hemodynamic instability due to risk for maternal hemorrhage. The ISTH-IG, ASH, and SCC-ISTH do not mention any recommendations or suggestions regarding the use of thrombolytic treatment.
The ACCP suggests the use of thrombolytic therapy in patients with massive PE (i.e., hypotension with systolic blood pressure $<90 \mathrm{mmHg}$ or when there are signs of obstructive shock) and specifically recommends peripheral thrombolysis using a peripheral vein over catheterdirected thrombolysis. In addition, ACCP suggests that in patients in whom therapeutic anticoagulation fails and who continue to have evidence of cardiopulmonary compromise, thrombolytic therapy may be beneficial. Similarly, the ACC mentions that systemic fibrinolysis is indicated in patients with significant hemodynamically unstable high risk PE and catheter-based therapies be reserved for situations that are not amenable to systemic fibrinolysis. Furthermore, hemodynamically stable patients with intermediate-low or intermediate-high risk $\mathrm{PE}$ should receive anticoagulation and fibrinolysis or catheter-directed therapies should be considered in cases of further deterioration. They also report that a multidisciplinary PE response team (PERT) may be helpful for intermediate and high risk patients with VTE and that catheter-directed therapies should be limited to most critical situations given minimal data demonstrating a mortality benefit.

\section{Duration of therapeutic anticoagulation}

The ACF recommends at least a 3-month course of anticoagulation for patients who are started on anticoagulation for a presumed provoked thrombus from the inflammatory state of CAC but did not have imaging available for confirmation. The ACF also recommends that standard anticoagulation guidelines be used to determine length of anticoagulation beyond the initial 3month period. The ACF mentions that an exception to the minimum 3-month course is in patients with recent bleeding or high risk of bleeding. In addition, the ACF comments that if confirmatory imaging cannot be obtained within a couple days of presumed diagnosis, it is possible that delayed imaging may show an absence of thrombus when one was present initially. Therefore, they recommend continuing empiric treatment for the minimum 3-month course. Similarly, the ACCP and SCCISTH recommend a minimum of 3 months of anticoagulation in those patients with confirmed PE or proximal DVT. The ISTH-IG, ASH, ACC, and CDC do not mention any recommendations or suggestions regarding the duration of therapeutic anticoagulation.

\section{Monitoring of anticoagulation}

\section{Monitoring of patients receiving LMWH}

None of the guidelines recommend or mentions routine monitoring for LMWH anticoagulation, with the exception of ISTH-IG which advises monitoring in patients with severe renal impairment receiving LMWH prophylactic anticoagulation. The ACF does not recommend 
dosing LMWH based on anti-Xa levels, and ACCP mentions that LMWH can be administered without laboratory monitoring in the majority of patients. The CDC, $\mathrm{ACC}$, and ASH do not have particular monitoring recommendations other than the current standard of care for other hospitalized patients.

\section{Monitoring of patients with prolonged PTT levels receiving therapeutic anticoagulation}

The ACF is the only society to recommend monitoring anti-Xa levels in patients with prolonged baseline PTT levels receiving therapeutic anticoagulation with UFH. While both ASH and ACCP do not make any specific recommendations regarding patients with prolonged PTT levels receiving therapeutic anticoagulation with UFH, ASH does mention that monitoring anti-Xa levels for patients receiving UFH may be necessary given artefactual increases in PTT and ACCP recommends monitoring anti-Xa levels in all patients receiving UFH given a potential for heparin resistance. The ISTH-IG, CDC, ACCP, ACC, and SCC-ISTH do not mention any recommendations or suggestions regarding monitoring of patients with prolonged PTT levels receiving therapeutic anticoagulation.

\section{Monitoring of patients receiving therapeutic anticoagulation}

None of the societal guidelines and recommendations make specific monitoring recommendations for patients receiving therapeutic anticoagulation with the exception of the ACF and ACCP which both recommend monitoring anti-Xa levels to monitor UFH due to baseline abnormalities in PTT. ACF does mention that it is reasonable to monitor anti-Xa or PTT in patients without prolonged PTT at baseline receiving UFH for therapeutic anticoagulation. ASH particularly mentions that anti-Xa monitoring of UFH may be necessary given artefactual increases in PTT secondary to lupus-like inhibitors. The SCC-ISTH does not make any specific recommendations regarding the use of anti-Xa levels to monitor UFH but does mention that expert clinical guidance statements and clinical pathways from large academic healthcare systems target an anti-factor Xa level of $0.3-0.7 \mathrm{IU} / \mathrm{mL}$ for UFH.

\section{Necessity of anticoagulation at discharge}

The CDC and ACF recommend against the routine use of prophylactic anticoagulation for patients discharged from the hospital. However, the CDC and ACF as well as ASH and SCC-ISTH mention that FDA-approved post-discharge prophylactic anticoagulation (PDPA) regimens (rivaroxaban and betrixaban) may be considered in patients with high risk for VTE and low risk for bleeding. Similarly, the ACCP mentions that PDPA can be considered in patients who are at low risk of bleeding if emerging data suggests that the risk of VTE outweighs the risk of bleeding. The ACF and SCC-ISTH both mention that enoxaparin in addition to betrixaban or rivaroxaban can be considered if PDPA is thought to be reasonable. The duration of anticoagulation recommended by ACF is based on the timing used in clinical trials which is 31-39 days for rivaroxaban, 35-42 days for betrixaban, and 6-14 days for enoxaparin. The SCCISTH recommends a duration of a minimum of 14 days and up to 30 days. ACC mentions that it is reasonable to consider extended prophylaxis with LMWH or DOACs for up to 45 days in patients at high risk for VTE (i.e., Ddimer $>2$ times ULN, reduced mobility, active cancer) and low risk of bleeding. As an alternative, ASH mentions that aspirin can also be considered based on studies for VTE prophylaxis in low risk patients after orthopedic surgery. Aspirin is not mentioned in any of the other guidelines and recommendations with the exception of SCC-ISTH which reports that none of their respondents recommended aspirin for post-discharge thromboprophylaxis.

\section{Correction of active bleeding}

In the setting of bleeding, the ISTH-IG recommends transfusion to keep platelet count $>50 \times 10^{9} / \mathrm{L}$, fibrinogen $>1.5 \mathrm{~g} / \mathrm{L}$, and PT ratio $<1.5$. ACC recommends platelet transfusion to maintain platelet count $>50 \times 10^{9} / \mathrm{L}$ in DIC and active bleeding $\left(>20 \times 10^{9} / \mathrm{L}\right.$ in patients at high risk of bleeding or requiring invasive procedures), fresh frozen plasma (FFP) (15 to $25 \mathrm{~mL} / \mathrm{kg}$ ) in patients with active bleeding with either prolonged PT or PTT ratios $(>1.5$ times normal) or decreased fibrinogen $(<1.5 \mathrm{~g} / \mathrm{L})$, and fibrinogen concentrate or cryoprecipitate in patients with persisting severe hypofibrinogenemia $(<1.5 \mathrm{~g} / \mathrm{L})$. Similarly, ASH recommends transfusion if platelets $<50 \times 10^{9} / \mathrm{L}$, INR $<1.8$, and fibrinogen $<1.5 \mathrm{~g} / \mathrm{L}$. ASH also recommends that in the setting of severe coagulopathy and bleeding, 4F-PCC be considered instead of plasma so as to prevent significant volume overload. ACC mentions that prothrombin complex concentrate is recommended if FFP is not possible and tranexamic acid should not be used routinely in patients with COVID-19-associated DIC given the existing data. Moreover, ASH mentions that transfusions to simply to correct laboratory abnormalities in the absence of bleeding may worsen disseminated thrombosis and deplete blood product resources without any evidence of improving clinical outcomes. Similarly, ACC mentions that correction of coagulopathy in unselected patients without significant bleeding is not recommended. 
Table 8 Ongoing clinical trials optimizing prophylactic anticoagulation regimens in COVID-19

\begin{tabular}{|c|c|c|c|}
\hline NCT number & Study name & Interventions & Sponsor \\
\hline NCT04409834 & $\begin{array}{l}\text { Prevention of Arteriovenous Thrombotic } \\
\text { Events in Critically-lll COVID-19 Patients } \\
\text { Trial }\end{array}$ & $\begin{array}{l}\text { Evaluation of varying anticoagulation } \\
\text { strategies including UFH IV, UFH SC, } \\
\text { enoxaparin } 1 \mathrm{mg} / \mathrm{kg} \text {, enoxaparin } \\
40 \mathrm{mg} \mathrm{SC} \text {, and clopidogrel }\end{array}$ & The TIMI Study Group \\
\hline NCT04367831 & $\begin{array}{l}\text { Intermediate or Prophylactic- Dose } \\
\text { Anticoagulation for Venous or Arterial } \\
\text { Thromboembolism in Severe COVID-19 }\end{array}$ & $\begin{array}{l}\text { Evaluation of prophylactic enoxaparin vs } \\
\text { intermediate dosing }\end{array}$ & Columbia University (USA) \\
\hline NCT04367831 & $\begin{array}{l}\text { Patient Characteristics, Outcome and } \\
\text { Thromboembolic Events Among Adult } \\
\text { Critically III COVID-19 Patients with } \\
\text { Different Anticoagulant Regimes }\end{array}$ & Completed dose finding study of tinzaparin & Karolinska Institute (Sweden) \\
\hline NCT04367831 & $\begin{array}{l}\text { Preventing COVID-19 Complications } \\
\text { with Low- and High-dose Anticoagulation }\end{array}$ & Evaluating low vs high dose enoxaparin & University Hospital Geneva (Switzerland) \\
\hline NCT04344756 & $\begin{array}{l}\text { Trial Evaluating Efficacy and Safety of } \\
\text { Anticoagulation in Patients With } \\
\text { COVID-19 Infection, Nested in the } \\
\text { Corimmuno-19 Cohort }\end{array}$ & Evaluation of tinzaparin vs UFH anticoagulation & $\begin{array}{l}\text { Assistance Publique }-\mathrm{H} \text { pitaux de Paris } \\
\text { (France) }\end{array}$ \\
\hline NCT04360824 & Covid-19 Associated Coagulopathy & $\begin{array}{l}\text { Evaluation of prophylactic vs intermediate dose } \\
\text { thromboprophylaxis }\end{array}$ & University of lowa (USA) \\
\hline NCT04360824 & $\begin{array}{l}\text { Full Dose Heparin Vs. Prophylactic or } \\
\text { Intermediate Dose Heparin in High } \\
\text { Risk COVID-19 Patients }\end{array}$ & $\begin{array}{l}\text { Evaluation of prophylactic vs intermediate dose } \\
\text { thromboprophylaxis }\end{array}$ & Northwell Health (USA) \\
\hline NCT04372589 & $\begin{array}{l}\text { Full Dose Heparin Vs. Prophylactic or } \\
\text { Intermediate Dose Heparin in High } \\
\text { Risk COVID-19 Patients }\end{array}$ & Evaluation of heparin dose strategy & University of Manitoba (Canada) \\
\hline
\end{tabular}

\section{Implications for clinical practice and future investigation}

These societal guidelines are based on consensus of expert opinion with limited evidence available in the form of robust clinical trials. Consequently, it is not surprising there are clinical issues that are either not addressed by the guidelines or have varying opinions. For instance, practitioners who deem a critically ill COVID-19 patient at high risk for thrombotic complication (e.g., trauma, cancer, antiphospholipid antibody) may decide to use a higher intensity prophylactic anticoagulation regimen consistent with the ACF guidelines rather than routine anticoagulation prophylactic regimen recommended by other societies. The major societal guidelines and recommendations share significant similarities, but also have some discrepancies. We recommend that providers manage their patients in the framework of these major societal guidelines, and where discrepancies do exist, decisions be made based on the practitioner's experience

Table 9 Ongoing clinical trials of therapeutic anticoagulation in COVID-19

\begin{tabular}{|c|c|c|c|}
\hline NCT number & Study name & Interventions & Sponsor \\
\hline NCT04377997 & $\begin{array}{l}\text { Safety and Efficacy of Therapeutic } \\
\text { Anticoagulation on Clinical Outcomes } \\
\text { in Hospitalized Patients With COVID-19 }\end{array}$ & Evaluation of therapeutic enoxaparin & Massachusetts General Hospital (USA) \\
\hline NCT04394377 & $\begin{array}{l}\text { Full Anticoagulation Versus Prophylaxis } \\
\text { in COVID-19: COALIZAO ACTION Trial }\end{array}$ & $\begin{array}{l}\text { Evaluation of therapeutic anticoagulation } \\
\text { with rivaroxaban } 20 \mathrm{mg} / \text { day vs prophylactic } \\
\text { enoxaparin } 40 \mathrm{mg} / \text { day }\end{array}$ & Brazilian Clinical Research Institute (Brazil) \\
\hline NCT04359277 & $\begin{array}{l}\text { A Randomized Trial of Anticoagulation } \\
\text { Strategies in COVID-19 }\end{array}$ & $\begin{array}{l}\text { Evaluation of therapeutic high dose } \\
\text { enoxaparin vs standard prophylactic dose }\end{array}$ & NYU Langone Health (USA) \\
\hline NCT04359277 & $\begin{array}{l}\text { Evaluation of therapeutic high dose } \\
\text { Enoxaparin versus standard prophylactic } \\
\text { dose } \\
\text { Anticoagulation in Critically III Patients } \\
\text { With COVID-19 (The IMPACT Trial) }\end{array}$ & $\begin{array}{l}\text { Evaluation of varying anticoagulation } \\
\text { regimens including enoxaparin, UFH, } \\
\text { fondaparinux, and argatroban }\end{array}$ & $\begin{array}{l}\text { Weill Medical College of Cornell University } \\
\text { (USA) }\end{array}$ \\
\hline NCT04362085 & $\begin{array}{l}\text { Coagulopathy of COVID-19: A Pragmatic } \\
\text { Randomized Controlled Trial of Therapeutic } \\
\text { Anticoagulation Versus Standard Care }\end{array}$ & $\begin{array}{l}\text { Evaluation of therapeutic anticoagulation } \\
\text { vs standard of care prophylaxis }\end{array}$ & St Michael's Hospital (Canada) \\
\hline
\end{tabular}


Table 10 Ongoing clinical trials of fibrinolytic therapy in COVID-19

\begin{tabular}{llll}
\hline NCT number & Study name & Interventions & Sponsor \\
\hline NCT04357730 & $\begin{array}{l}\text { Fibrinolytic Therapy to Treat } \\
\text { ARDS in the Setting of COVID-19 } \\
\text { Infection }\end{array}$ & $\begin{array}{l}\text { Phase 2a trial comparing } 50 \mathrm{mg} \text { and } \\
100 \mathrm{mg} \text { doses of alteplase }\end{array}$ & Denver Health and Hospital Authority (USA) \\
NCT04356833 & $\begin{array}{l}\text { Nebulised rtPA for ARDS Due to } \\
\text { COVID-19 (PACA) }\end{array}$ & $\begin{array}{l}\text { Phase 2 trial evaluation nebulized tissue } \\
\text { plasminogen activator in COVID-19 ARDS }\end{array}$ & University College London (UK) \\
\hline
\end{tabular}

Abbreviations: ARDS acute respiratory distress syndrome, COVID-19 coronavirus disease $2019, \mathrm{mg}$ milligrams, Rt-PA recombinant tissue plasminogen activator

and their understanding of a patient's medical history, clinical course, and perceived risk.

Based on this review and comparison of the societal guidelines, there are a number of unaddressed issues that warrant further investigation and incorporation into updated guidelines. Further studies of COVID-19 pathophysiology are required to elucidate the mechanisms of coagulation disruption in order to identify potential pharmacologic targets and new biomarkers for risk stratification. Large randomized control trials are needed to investigate the optimal prophylactic anticoagulation regimen, the utility of intermediate and therapeutic anticoagulation, and the use of fibrinolytic therapy in COVID-19 patients. There are several clinical trials currently in the ClinicalTrials.gov database focused on optimizing prophylactic anticoagulation regimens (8 total) (Table 8 ), therapeutic anticoagulation (5 total) (Table 9), and fibrinolytic therapy ( 2 total) (Table 10) in COVID19 patients [14], and we eagerly await those results. Further guidance from prospective studies is required to guide the clinical significance of biomarkers (e.g., Ddimer, antiphospholipid, and lupus anticoagulant antibodies) in risk stratification and treatment of CAC.

\section{Conclusions}

There are significant similarities and differences surrounding the major societal recommendations and guidelines regarding risk stratification and management of COVID-19-associated coagulopathy in regard to use of laboratory makers, prevention, treatment, and monitoring of VTE, and post-discharge thromboprophylaxis. In addition, there are a number of unanswered questions that warrant further investigation. It is incumbent on the clinicians to remain updated on emerging literature in this area in order to optimize the care of critically ill patients with COVID-19.

\footnotetext{
Abbreviations

ACF: Anticoagulation Forum; ACC: American College of Cardiology; ACCP: American College of Chest Physicians; ASH: American Society of Hematology; ARDS: Acute respiratory distress syndrome; CAC: COVID-19associated coagulopathy; CDC: Centers for Disease Control and Prevention; COVID-19: Coronavirus disease 2019; CRRT: Continuous renal replacement therapy; DVT: Deep venous thrombosis; DIC: Disseminated intravascular coagulation; ECMO: Extracorporeal membrane oxygenation;

ISTH: International Society on Thrombosis and Haemostasis; LMWH: Low molecular weight heparin; PT: Prothrombin time; PTT: Partial thromboplastin time; PE: Pulmonary embolism; SCC: Scientific and Standardization
}

Committee; STEMI: ST elevation myocardial infarction; UFH: Unfractionated heparin; ULM: Upper limit of normal

\section{Acknowledgements \\ None.}

\section{Authors' contributions}

$A F, R P R, C T R, B K B, E A B$, and MGC wrote and reviewed the manuscript. The authors read and approved the final manuscript.

\section{Funding \\ None.}

Availability of data and materials

Not applicable.

Ethics approval and consent to participate

Not applicable.

\section{Consent for publication}

Not applicable.

\section{Competing interests}

RR is on the Board of Directors for the Pulmonary Embolism Response Team (PERT) Consortium and has no other competing interests as it relates to this manuscript. All other authors declare to have no competing interests.

\section{Author details}

${ }^{1}$ Division of Critical Care, Department of Anesthesia, Critical Care and Pain Medicine, Massachusetts General Hospital, Boston, USA. ${ }^{2}$ Division of Hematology and Oncology, Massachusetts General Hospital, 55 Fruit Street, Boston, MA, USA. ${ }^{3}$ Division of Hematology and Oncology, National Institutes of Health, Bethesda, MD, USA. ${ }^{4}$ Department of Surgery, Division of Trauma, Emergency Surgery, and Surgical Critical Care, Massachusetts General Hospital, Boston, MA, USA. ${ }^{5}$ Division of Cardiac Anesthesia and Critical Care, Department of Anesthesia, Critical Care and Pain Medicine, Massachusetts General Hospital, Boston, USA.

Received: 17 August 2020 Accepted: 2 September 2020

Published online: 16 September 2020

\section{References}

1. Connors JM, Levy JH. COVID-19 and its implications for thrombosis and anticoagulation. Blood. 2020;135(23):2033-40.

2. Danzi GB, Loffi M, Galeazzi G, Gherbesi E. Acute pulmonary embolism and COVID-19 pneumonia: a random association? Eur Heart J. 2020;41(19):1858.

3. Martinelli I, Ferrazzi E, Ciavarella A, et al. Pulmonary embolism in a young pregnant woman with COVID-19. Thromb Res. 2020;191:36-7.

4. Zhang Y, Xiao M, Zhang $\mathrm{S}$, et al. Coagulopathy and antiphospholipid antibodies in patients with covid-19. N Engl J Med. 2020;382(17):e38.

5. Al-Samkari H, Karp Leaf RS, Dzik WH, et al. COVID and coagulation: bleeding and thrombotic manifestations of SARS-CoV2 infection. Blood. 2020;136(4): 489-500.

6. National Institutes of Health. Coronavirus disease 2019 (COVID-19) treatment guidelines. 2020. https://www.covid19treatmentguidelines.nih.gov/. (Accessed 25 May 2020).

7. Thachil J, Tang N, Gando S, et al. ISTH interim guidance on recognition and management of coagulopathy in COVID-19. J Thromb Haemost. 2020;18(5): 1023-6. 
8. American Society of Hematology. COVID-19 and VTE/anticoagulation: frequently asked questions. June 23, 2020 2020. https://www.hematology. org/covid-19/covid-19-and-vte-anticoagulation (Accessed 25 June 2020).

9. American Society of Hematology. COVID-19 and coagulopathy: frequently asked questions. June 23, 2020 2020. https://www.hematology.org/covid-1 9/covid-19-and-coagulopathy (Accessed 25 June 2020).

10. Moores LK, Tritschler T, Brosnahan S, et al. Prevention, diagnosis and treatment of venous thromboembolism in patients with COVID-19: CHEST Guideline and Expert Panel Report. Chest. 2020;158(3):1143-63.

11. Spyropoulos AC, Levy JH, Ageno W, et al. Scientific and Standardization Committee communication: clinical guidance on the diagnosis, prevention and treatment of venous thromboembolism in hospitalized patients with COVID-19. J Thromb Haemost. 2020;18(8):1859-65.

12. Barnes GD, Burnett A, Allen A, et al. Thromboembolism and anticoagulant therapy during the COVID-19 pandemic: interim clinical guidance from the anticoagulation forum. J Thromb Thrombolysis. 2020;50(1):72-81.

13. Bikdeli B, Madhavan MV, Jimenez D, et al. COVID-19 and thrombotic or thromboembolic disease: implications for prevention, antithrombotic therapy, and follow-up: JACC state-of-the-art review. J Am Coll Cardiol. 2020;75(23):2950-73.

14. National Library of Medicine (US). Clinical Trials. 2020. https://www. ClinicalTrials.gov. (Accessed 5 June 2020).

\section{Publisher's Note}

Springer Nature remains neutral with regard to jurisdictional claims in published maps and institutional affiliations. 